\title{
Occlusal Surface
}

National Cancer Institute

\section{Source}

National Cancer Institute. Occlusal Surface. NCI Thesaurus. Code C52591.

The biting surfaces of the premolar and molar teeth. 